\begin{tabular}{|c|c|}
\hline Publisher & : John Wiley \& Sons, Inc. \\
\hline Location & : Hoboken, USA \\
\hline DOI & : 10.1002/(ISSN)1096-9861 \\
\hline ISSN (print) & : 0021-9967 \\
\hline ISSN (electronic) & : 1096-9861 \\
\hline ID (product) & : CNE \\
\hline Title (main) & : Journal of Comparative Neurology \\
\hline Title (short) & : J Comp Neurol \\
\hline Copyright (publisher) & : (C) 2020 Wiley Periodicals, Inc. \\
\hline DOI & $:$ : 10.1002/cne.24913 \\
\hline ID (unit) & : CNE24913 \\
\hline ID (society) & : JCN-20-0074 \\
\hline Count (pageTotal) & $: 14$ \\
\hline Title (articleCategory) & : RESEARCH ARTICLE \\
\hline Title (tocHeading1) & : RESEARCH ARTICLES \\
\hline Copyright (publisher) & : (C) 2020 Wiley Periodicals, Inc. \\
\hline Event (manuscriptReceived) & : 2020-03-10 \\
\hline Event (manuscriptAccepted) & : 2020-03-12 \\
\hline Event (xmlCreated) & : 2020-04-01 (SPi Global) \\
\hline Numbering (pageFirst) & $: \mathrm{n} / \mathrm{a}$ \\
\hline Numbering (pageLast) & $: \mathrm{n} / \mathrm{a}$ \\
\hline Object Name (figure) & : FIGURE \\
\hline Link (toTypesetVersion) & : file:cne24913.pdf \\
\hline Link (toAuthorManuscriptVersion) & : file:cne24913_am.pdf \\
\hline
\end{tabular}

Short Authors: Holland and Somorjai

\title{
The sensory peripheral nervous system in the tail of a cephalochordate studied by serial blockface scanning electron microscopy
}

$<<$ Query: Please confirm that given names (blue) and surnames/family names (vermilion) have been identified and spelled correctly. Ans: given and family names are correct for both authors $>>$ Nicholas D. $<<$ Query: Please check if link to ORCID is correct. Ans: Orchid is correct $>>$ Holland ${ }^{* 1}$, Ildiko M. L. Somorjai ${ }^{2}$

${ }^{1}$ Marine Biology Research Division, Scripps Institution of Oceanography, University of California at San Diego, La Jolla, California, USA

${ }^{2}$ School of Biology, University of Saint Andrews, St Andrews, UK

Nicholas [?spiepr146?]D. Holland: nholland@ucsd.edu

*Correspondence to:

\section{Correspondence}


Nicholas D. Holland, Marine Biology Research Division, Scripps Institution of Oceanography, University of California at San Diego, La Jolla, CA 92093.

Email:nholland@ucsd.edu

\section{Abstract}

Serial blockface scanning electron microscopy (SBSEM) is used to describe the sensory peripheral nervous system (PNS) in the tail of a cephalochordate, Asymmetron lucayanum. The reconstructed region extends from the tail tip to the origin of the most posterior peripheral nerves from the dorsal nerve cord. As peripheral nerves ramify within the dermis, all the nuclei along their course belong to glial cells. Invaginations in the glial cell cytoplasm house the neurites, an association reminiscent of the nonmyelinated Schwann cells of vertebrates. Peripheral nerves pass from the dermis to the epidermis via small fenestrae in the sub-epidermal collagen fibril layer; most nerves exit abruptly, but a few run obliquely within the collagen fibril layer for many micrometers before exiting. Within the epidermis, each nerve begins ramifying repeatedly, but the branches are too small to be followed to their tips with SBSEM at low magnification (previous studies on other cephalochordates indicate that the branches end freely or in association with epidermal sensory cells). In Asymmetron, two morphological kinds of sensory cells are scattered in the epidermis, usually singly, but sometimes in pairs, evidently the recent progeny of a single precursor cell. The discussion considers the evolution of the sensory PNS in the phylum Chordata. In cephalochordates, Retzius bipolar neurons with intramedullary perikarya likely correspond to the Rohon-Beard cells of vertebrates. However, extramedullary neurons originating from ventral epidermis in cephalochordates (and presumably in ancestral chordates) contrast with vertebrate sensory neurons, which arise from placodes and neural crest.

\section{Graphical Abstract}

Cephalochordates (amphioxus or lancelets) are basal in the phylum Chiordata and can exemplify the relatively simple developmental and anatomical starting conditions likely to have evolved into more complex vertebrate features. Here we use serial blockface scanning electron microscopy to reconstruct the sensory peripheral nervous system in the tail of a lancelet. The nerves (glial cell/neurite complexes) branch within the dermis and then exit to the epidermis to associate with the perikarya of two kinds of ciliated sensory neurons. The results indicate that cephalochordate neuroglia have an intramedullary origin. Moreover, we suggest that the peripheral nerves in the dermis are, at least in part, comparable to Rohon-Beard cells of vertebrates, whereas, in contrast, the placode- and neural crest-derived peripheral neurons of vertebrates are evolutionary novelties that appear to have supplanted the epidermal sensory receptors of cephalochordates.

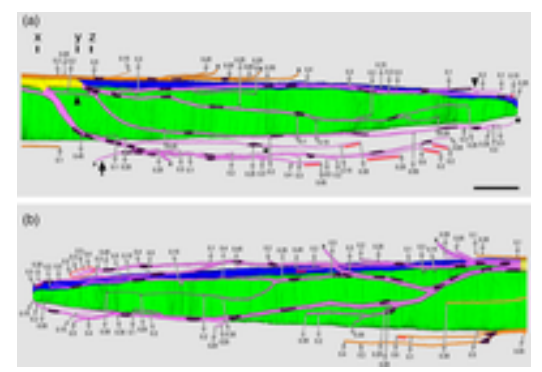

Keywords: amphioxus; Cephalochordata; glia; lancelet; peripheral nervous system; SBSEM

\section{INTRODUCTION}

Cephalochordates, commonly called amphioxus or lancelets, are the earliest branching clade in the phylum Chordata. Thus, they can provide insights into the relatively simple foundations on which much more elaborate vertebrate characters were built-a good example is neural crest evolution (Holland, Panganiban, Henyey, \& 
Holland, 1996). One such character is the simple peripheral nervous system (PNS) of cephalochordates. It has neither ganglia nor an autonomic component. Moreover, neither neural crest nor placodes play a part in its development, and the distinction between cranial and spinal nerves is inconspicuous (Balfour, 1885; Fritzsch \& Northcutt, 1993; Holland, 2009).

There have been many previous publications on the cephalochordate PNS, all limited to species in the genus Branchiostoma. Some of these descriptions were focused on embryos and larvae (Kaltenbach, Yu \& Holland, 2009; Lu, Luo, \& Yu, 2012; Yasui, Tabata, Ueki, Uemura, \& Zhang, 1998; Zieger, Garbarino, Robert, $\mathrm{Yu}$, Croce, Candiani, \& Schubert, 2018), and others concerned postmetamorphic and adult stages. These latter studies have spanned the range from low-resolution descriptions of whole animals (Retzius, 1898) through more detailed observations on smaller tissue samples (Demski, Beaver, \& Morrill, 1996; Dogiel, 1903; Fusari, 1889; Heymans \& van der Stricht, 1898; Johnston, 1905; Kutchin, 1913; Langerhans, 1876; Lele, Palmer, \& Weddell, 1958; Reichert, 1870; Rohon, 1882) to fine-scale descriptions with transmission electron microscopy (TEM; Lacalli \& Hou, 1999; Peters, 1963; Ruppert, 1997; Schulte \& Riehl, 1977; Welsch, 1968). Because the TEM was based, at best, on limited serial sectioning, some of the results were difficult to place within the context of the anatomy as a whole. To help bridge gaps left by these earlier studies, the present investigation uses serial blockface scanning electron microscopy (SBSEM) to demonstrate the fine details of the PNS within a body region comprehensively reconstructed in three dimensions (3D). To date, SBSEM has most often been used for describing TEM-level details of cells within relatively small tissue volumes. In contrast, the technique has only infrequently been employed to describe larger body regions (Holland, 2018), first because such studies require relatively low magnification with concomitant loss of resolution, and second because extensive $3 \mathrm{D}$ reconstructions are time consuming. In spite of these drawbacks, high volume SBSEM, as exemplified by the present study, can provide new insights and serve to put less synoptic earlier work into a broad context.

The cephalochordate described here, Asymmetron lucayanum, the Bahamas lancelet, has a relatively small adult size (on the order of $2 \mathrm{~cm}$ ), which is advantageous for reconstructing body regions in $3 \mathrm{D}$. We focus here on the tail tip, which extends as a slender caudal process (Andrews, 1893), a well-defined body part that includes the region where the dorsal nerve cord gives rise to the most posterior peripheral nerves and then continues as a filum terminale. The peripheral nerves accompanying the filum terminale posteriorly are comparable to the cauda equine of some vertebrates. In the tail region investigated, the PNS is entirely sensory and is divisible into interconnected dermal and epidermal compartments. It helps to keep in mind that what are called nerves in the dermal compartment are actually complexes of glial cells and neurites. The nuclei associated with these nerves all belong to glial cells and not to the neuronal component-the perikarya of the latter either lie within the dorsal nerve cord (Bone, 1959) or comprise sensory cell bodies in the epidermis (Lacalli \& Hou, 1999).

Here we provide a synoptic view of the PNS and its associated glia within the dermis, determine the size and distribution of nerves traversing fenestrae in the collagen fibril layer just beneath the dermal-epidermal junction, and describe the ciliated sensory cells within the epidermis. The discussion speculates that ancestral chordates resembled extant cephalochordates in having a sensory PNS comprising two classes of neurons: namely, those with intramedullary perikarya and those with extramedullary perikarya located in the epidermis. During chordate evolution, the component with intramedullary perikarya evidently carried over into vertebrates as Rohon-Beard cells, while the component with extramedullary perikarya originating from ventral epidermis was completely replaced in all vertebrates by sensory neurons differentiating from placodes and neural crest.

\section{MATERIALS AND METHODS}

\subsection{Animals}

Adults of Asymmetron lucayanum were sieved from the sandy substratum at ankle depth at low tide in the Bimini lagoon, Bahamas. A map of the collecting site (GPS coordinates: $25.72297^{\circ} \mathrm{N}, 79.29288^{\circ} \mathrm{W}$ ) is in 
Holland (2011). The animals in the present study were $1.8 \mathrm{~cm}$ long, the commonest size class in the collection. These were fixed for light and electron microscopy a few days after collection.

\subsection{Light microscopy and conventional SEM}

Inter-animal variability in the distribution of peripheral nerves was estimated by light microscopy of serial semi-thin sections of six specimens. Fixation was for several days at $4{ }^{\circ} \mathrm{C}$ in $4 \%$ paraformaldehyde in $0.1 \mathrm{M}$ MOPS buffer at $\mathrm{pH} 7.4$ containing $0.5 \mathrm{M} \mathrm{NaCl}, 1 \mathrm{mM}$ EGTA, and $2 \mathrm{mM} \mathrm{MgSO}_{4}$. After fixation, the anterior $1.5 \mathrm{~cm}$ of each animal was cut away, leaving the posterior region to be processed for light microscopy. Fixed specimens were washed for $1 \mathrm{~min}$ in distilled water, stained in toto in $0.2 \%$ Ponceau $\mathrm{S}$ in $0.1 \%$ aqueous acetic acid for $90 \mathrm{~min}$ at room temperature, washed for $10 \mathrm{~min}$ in distilled water, dehydrated through an ethanol series, and embedded in Spurr's resin (Polysciences, Warrington, PA). After the resin was polymerized overnight at $70^{\circ} \mathrm{C}$, a complete series of semi-thin $(2.5-\mu \mathrm{m})$ sections was cut from each block with glass knives. Each section was transferred to a drop of water on a glass slide, flattened by evaporating the water on a hot plate, stained through the resin with $0.1 \%$ aqueous azure A, washed briefly in distilled water, dried, and mounted in immersion oil. For conventional SEM, the tails of six adults were fixed overnight at $4^{\circ} \mathrm{C}$ in $2 \%$ glutaraldehyde-sea water, rinsed for $30 \mathrm{~s}$ in distilled water, dehydrated in an ethanol series, transferred to hexamethyldisilazane (Braet, De Zanger, \& Wisse, 1997), and air-dried. The dried specimens were mounted on double-sided adhesive tape affixed to SEM stubs, coated with iridium, and viewed in a Hitachi S480o SEM.

\subsection{SBSEM and 3-D reconstructions}

For SBSEM, four tails were processed for cross-sectioning. The best oriented one is illustrated here, although ancillary observations were made on the others before sectioning was terminated early when unfavorable orientation in the block became evident. The primary fixation was for 2 weeks at $4^{\circ} \mathrm{C}$ in $0.15 \mathrm{M}$ cacodylate buffer (pH 7.4) containing 2.5\% glutaraldehyde, $2 \%$ formaldehyde, and $2 \mathrm{mM} \mathrm{CaCl}_{2}$ (Deerinck, Bushong, LevRamm, Tsien, \& Ellisman, 2010). After primary fixation, the samples were exposed successively to reduced osmium tetroxide, thiocarbohydrazide, osmium tetroxide, uranyl acetate, and lead aspartate under conditions in table 1 in Wanner, Genoud, \& Friedrich (2016). Following ethanol dehydration at $4^{\circ} \mathrm{C}$, the specimens were transferred through acetone and embedded in Durcupan resin.

The SBSEM was carried out with a 3View system (Gatan, Pleasanton, CA) installed in a Zeiss Merlin SEM. Each resin-embedded sample is placed in a scanning electron microscope specimen chamber containing an ultramicrotome (Denk \& Horstman, 2004; Peddie \& Collinson, 2014; Titze \& Genoud, 2016). After the microscope records, an image of the blockface by backscattered electrons, the microtome shaves away a thin section from the specimen to expose a new blockface. This alternation of scanning and shaving generates uninterrupted serial images, each superficially resembling a conventional transmission electron micrograph. In the present study, blockfaces were scanned every $0.25 \mu \mathrm{m}$. From the most favorably oriented tail tip, we scanned a total of 2,240 block faces. The SBSEM image series was converted to 3D with Reconstruct software, available gratis from http://www.bu.edu/neural/Reconstruct.html (Borrett \& Hughes, 2016; Fiala, 2005). In the reconstructions, the tissues were depicted as continuous Boissonnat surfaces (in some instances, rendered semitransparent to reveal the position of nuclei within the cells). Because the sections were at relatively low magnification (and thus at relatively low resolution), it was not possible to visualize intercellular boundaries in some of the tissues. Even so, the distribution of such cells can be shown by reconstructing their constituent nuclei. Finally, all cross-sections here are oriented as if viewed from the posterior end of the animal; thus leftand right-side structures are, respectively, toward the left and right in all the figures.

\subsection{Quantification and statistics}

From the SBSEM data, we measured the diameters of all 117 nerves passing through fenestrae in the collagen fibril layer on the left and right side of the region studied. We also evaluated the spatial pattern of fenestrae in the collagen fibril layer and the distribution of epidermal sensory cells by measuring nearest neighbor 
relationships. A first index of dispersion was calculated from the SBSEM reconstruction of fenestrae on the left side of the tail, and a second index of dispersion was calculated for the sensory cells (Type I and Type II together) in conventional SEM of a comparable area on the left side of the tail of another animal; this was preferable to measuring sensory cells in the SBSEM reconstruction, some of which could not be identified with certainty. After the indices of dispersion were corrected for boundary strip errors (Donnelly, 1978), the two data sets were compared.

SBSEM data were also used to examine the distances separating the two kinds of epidermal sensory cells from the fenestrae on either side of the tail area studied. For this comparison, we included only sensory cells that were clearly identifiable with SBSEM on the left and right sides (in all, 39 Type I cells and 49 Type II cells). Images of these sensory cells were superimposed on the map of the fenestrae on the appropriate side of the tail, and the distance from the basal pole of each cell to the nearest fenestra was measured and plotted in $4-\mu \mathrm{m}$ increments.

\section{RESULTS}

\subsection{The PNS in the tail as seen by light microscopy}

An adult specimen of Asymmetron lucayanum (Figure 1a), as already mentioned, has a post-anal tail terminating posteriorly in a caudal process (Figure $1 \mathrm{~b}$ ). The core tissues running the entire length of the tail are the dorsal nerve cord and notochord (Figure 1c,d). In the caudal process, the coelomic mesoderm is much reduced, lacking musculature and any segmental organization. As a consequence, none of the peripheral nerves studied here run within collagenous intersegmental myocommata (a conspicuous feature of the PNS in more anterior body regions).

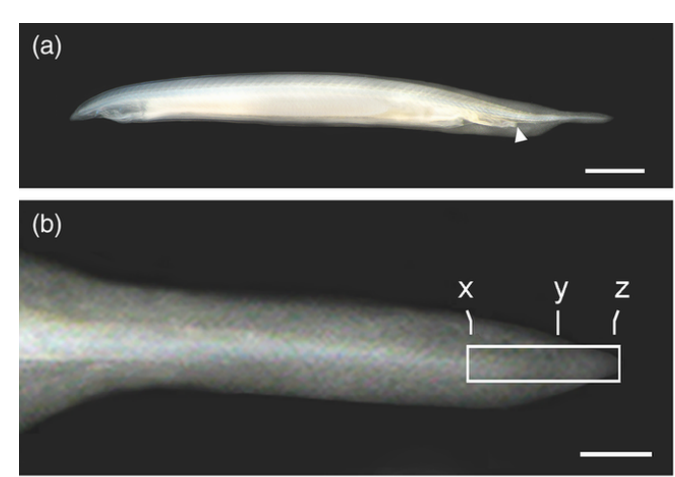

(c)

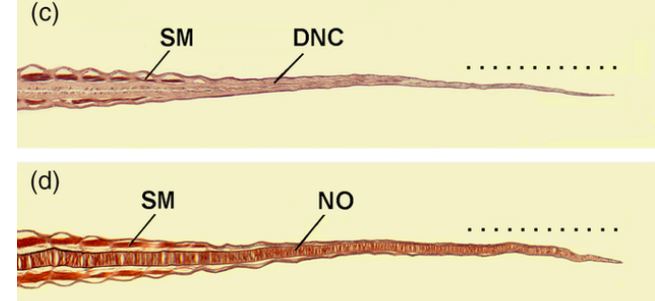

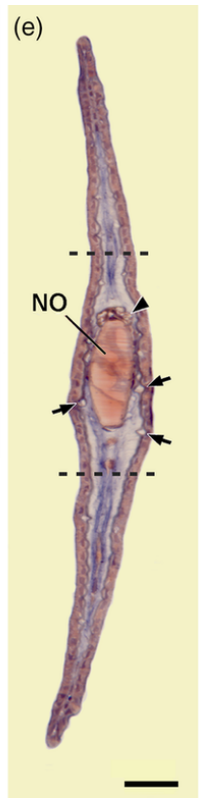

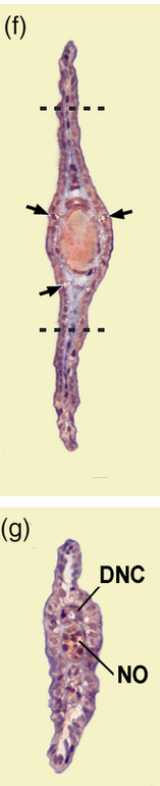

FIGURE 1 Bahamas lancelet (Asymmetron lucayanum). (a) Living adult; anus indicated by arrowhead. Scale line $=2 \mathrm{~mm}$. (b) Tail of foregoing with studied region in rectangle; lower case letters show levels of cross-sections in 1e, g; scale line (also applicable to 1c, d) $=250 \mu \mathrm{m}$. (c) Frontal section through tail at level of dorsal nerve cord (DNC); segmented muscles (SM) toward left; length of SBSEM reconstruction indicated by dotted line. (d) Frontal section through tail at level of notochord (NO); segmented muscles (SM) toward left; length of SBSEM reconstruction indicated by dotted line. (e) Cross-section at Level $x$ in 1b; fin regions dorsal and ventral to dashed lines outside SBSEM field of view; dorsal to notochord (NO), 
the dorsal nerve cord has a neuropil component (arrowhead); arrows point to some large peripheral nerves; scale line (also applicable to 1f, g) $=25 \mu \mathrm{m}$. (f) Cross-section at Level $y$ in $1 \mathrm{~b}$; neural tube no longer includes neuropil; fin regions dorsal and ventral to dashed lines outside SBSEM field of view. (g) Crosssection at Level $z$ in $1 \mathrm{~b}$, near blind posterior terminations of dorsal nerve cord (DNC) and notochord (NO)

Bordering the tail are dorsal and ventral fins, each consisting of a broad flange of dermal matrix overlain by a single-layered epidermis. As shown by the dashed lines in Figure 1e,f, the entire height of the fins could not be included in the field of view of our SBSEM except at the extreme posterior (Figure 1g). By light microscopy of $2.5-\mu \mathrm{m}$ thick plastic sections, the peripheral nerves are not detectable in frontal view (Figure 1c,d), and, in cross-sections, only the nerves of large to medium diameter (Figure 1e,f, arrows) can be unequivocally identified. When these detectable nerves are compared among six different animals sectioned at equivalent levels of the tail, their branching patterns in the dermis differ considerably. This finding agrees with the extensive inter-animal variability in the distribution of peripheral nerve branches long known for Branchiostoma (Kutchin, 1913).

\subsection{Extracellular components of the dermis}

For most of their length, the peripheral nerves run through a dermis (DE in Figure 2a,c), where even those with the smallest diameters (for example, the arrowed nerves in Figure 2c,d) can be unequivocally demonstrated. The dermis comprises a voluminous extracellular matrix that is finely granular (Figure $2 b, d$ ) and a bordering collagen fibril layer about $1 \mu \mathrm{m}$ thick (FL in Figure 2b). Confusingly, the fibril layer has several synonyms in the literature: Grenzlamelle (Langerhans, 1876), cuticle (Fusari, 1889), homogene subepithelial Schicht (Dogiel, 1903), corium (Studnicka, 1909), and dermal collagenous mesh (Ruppert, 1997). Although our SBSEM does not resolve the detailed structure of the fibril layer, our unpublished TEM shows that, as in Branchiostoma (Welsch, 1968), the fibrils in Asymmetron each have a diameter about $50 \mathrm{~nm}$ and are aligned in thin abutting layers that are arranged orthogonally (i.e., fibrils in adjacent layers are oriented roughly at right angles to one another).

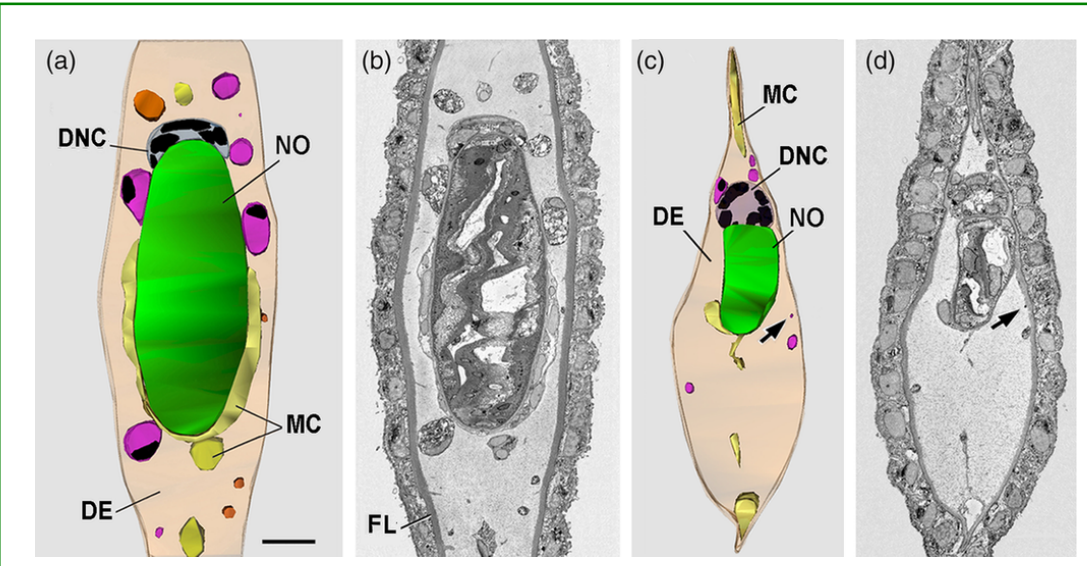

FIGURE 2 (a) Reconstruction of a $5-\mu \mathrm{m}$ thick stack of SBSEM sections toward the anterior end of the sampled region, showing voluminous extracellular matrix of dermis (DE), dorsal nerve cord (DNC; semitransparent to show black nuclei), mesoderm cells (MC), and notochord (NO); epidermis is omitted. Peripheral nerves are semitransparent to show black nuclei; the orange nerves and pink nerves arise from the DNC, respectively, anterior and within the sampled region; scale line (also applicable to $2 \mathrm{~b}-\mathrm{d})=10 \mu \mathrm{m}$. (b) Single section midway in reconstruction a; the peripheral component of the dermis is the collagen fibril layer (FL). (c) Reconstruction of a 5 - $\mu$ m thick stack of SBSEM sections toward the posterior end of the sampled region; abbreviations are as in 2a; the arrow indicates a very small nerve. (d) Single section midway in reconstruction c; the arrow indicates a very small nerve 


\subsection{Peripheral nerves in the dermis}

All the peripheral nerves running in the dermis are complexes of neurites and glial cells (the latter are described in detail in section 3.5). Figure 3a,b is SBSEM reconstructions of the peripheral nerves, respectively, on the left and right sides of the tail region studied. These peripheral nerves are the most posterior ones in the body. After originating from the dorsal nerve cord, they extend posteriorly, branching through several orders of dichotomy (this pattern is interrupted in a few places by anastomoses). As a rule, the peripheral nerves within the dermis (Figure 4a, arrowhead) run in close proximity to the inner side of the collagen fibril layer although they can, in places, run somewhat deeper in the dermal matrix (Figure 4b, arrowhead). Some older references (like Dogiel, 1903) described a fine plexus of peripheral nerves associated with the inner surface of the fibril layer in Branchiostoma; in contrast, our SBSEM reveals no such plexus in Asymmetron. The white arrows in Figure $3 a, b$ indicate locations where the peripheral nerves of the dermis connect with the epidermal component of the PNS (described in detail in sections 3.6 and 3.7).

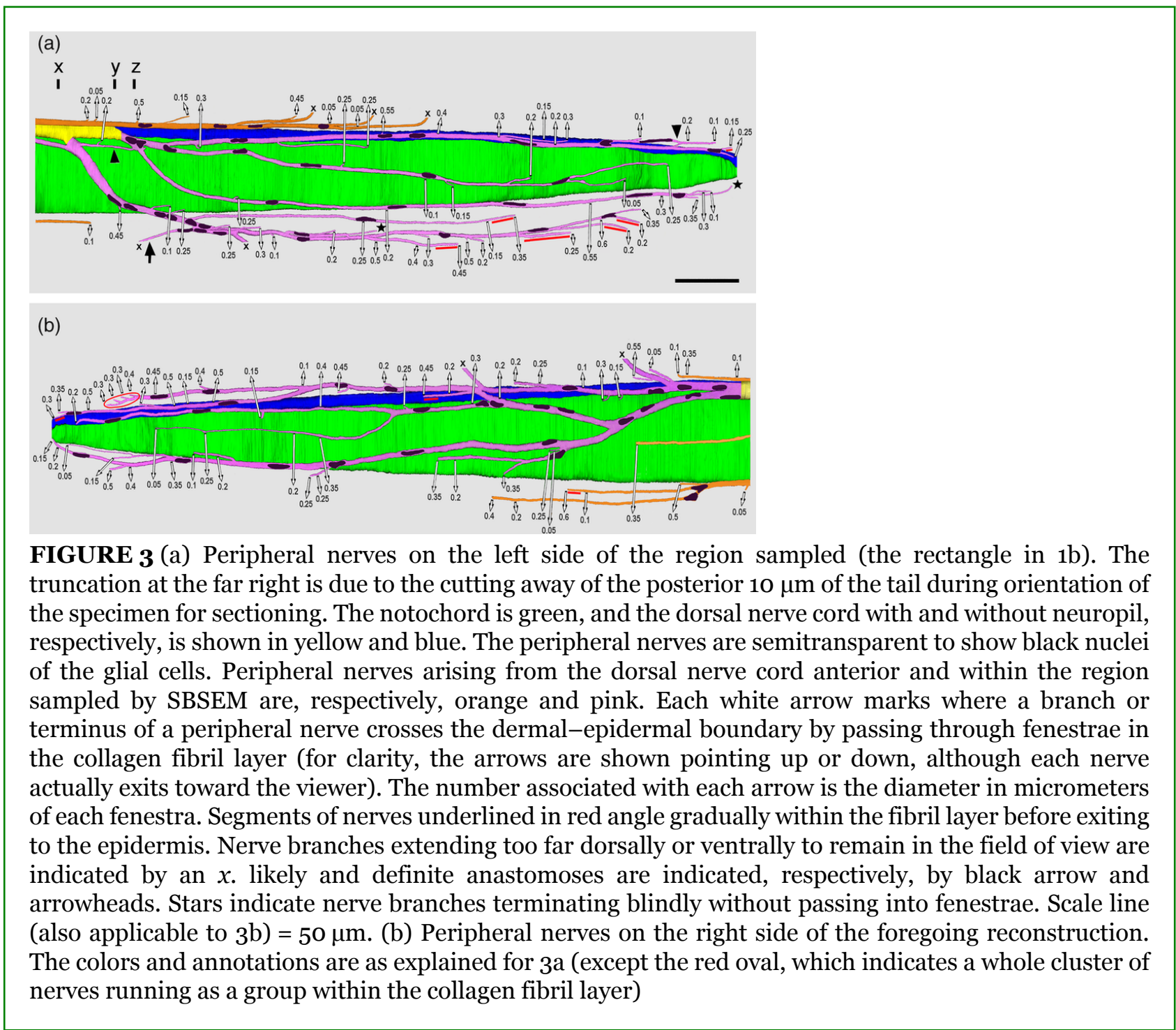



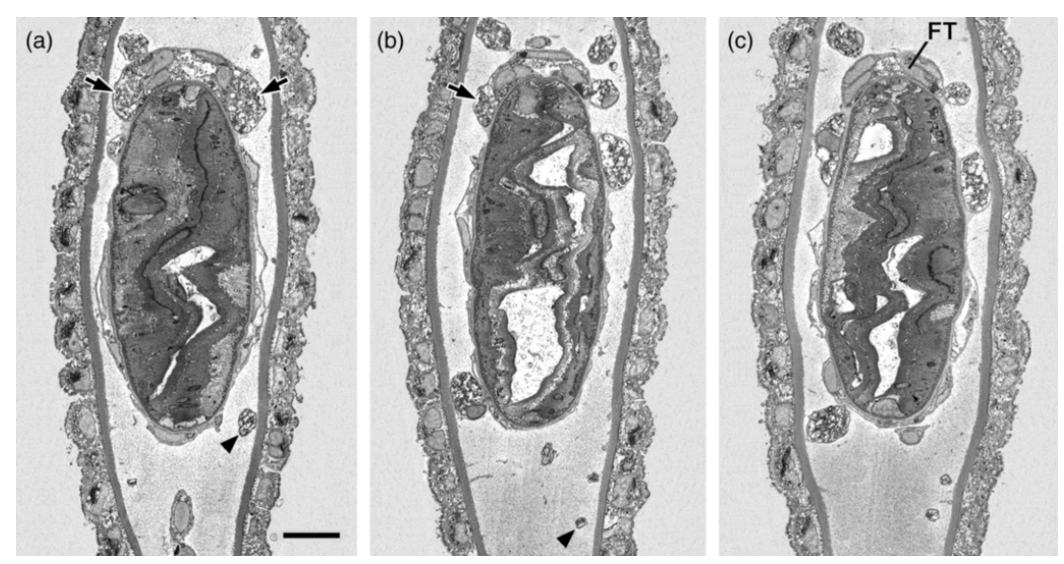

FIGURE 4 (a) Single SBSEM cross-section through Level $x$ in 3 a, showing neuropil associated with the left and right sides (arrows) of the dorsal nerve cord; the arrowhead indicates a peripheral nerve running right next to the fibril layer; scale line (also applicable to $4 \mathrm{~b}, \mathrm{c}$ ) $=10 \mu \mathrm{m}$. (b) Cross-section through Level $y$ in 3a, showing neuropil (arrow) associated with only left side of dorsal nerve cord; the arrowhead indicates a peripheral nerve running in the dermal matrix a little separated from the fibril layer. (c) Crosssection through Level $z$ in 3 a showing the nerve cord, now a filum terminale (FT) without any neuropil

\subsection{Filum terminale}

The peripheral nerves described in the present study diverge from the dorsal nerve cord at a level where the latter includes a neuropil component (Figure 4a,b, arrows). As the most posterior peripheral nerves originate, all of the neuropil accompanies them (Figure $4 \mathrm{~b}, \mathrm{c}$ ), and the remainder of the dorsal nerve cord-evidently consisting entirely of ependymal glial cells-continues toward the tail tip as a filum terminale (FT in Figure 4c). According to Olsson (1955), the filum terminale of Branchiostoma consists entirely of glia without any neural elements and dilates into a conspicuous ampulla at the tip. In contrast, subsequent work by Soledad-Ruiz \& Anadon (1991) showed that the Branchiostoma filum terminale has neurosecretory neurites running at the base of the glial cells. In the present study, we found neither a marked ampulla nor any neurosecretory neurites in the filum terminale of Asymmetron. Olsson (1955) also found a Reissner's fiber running within the neurocoel of Branchiostoma; however, if Asymmetron has a Reissner's fiber, it was not detectable in our lowresolution SBSEM.

\subsection{Glial cells of the PNS}

The glial cells accompanying the PNS neurites in the dermis are derived from the neuropil of the dorsal nerve cord (section 3.4). Recent work on vertebrates also indicates that some of the PNS glial cells originate within the central nervous system (Suter \& Jaworski, 2019) and not exclusively from neural crest as previously thought (Butler \& Bronner, 2015). In the light of this more recent point of view, it seems likely that an intramedullary origin for PNS glia, as seen in cephalochordates, represents the ancestral condition in the phylum Chordata.

As already mentioned, the peripheral nerves running through the dermis (Figure 3a,b) are characterized by nuclei belonging to their glial and not their neural component. Each of the 68 glial cell nuclei enumerated here averages about $15 \mu \mathrm{m}$ long and $3 \mu \mathrm{m}$ wide. Low magnification SBSEM lacks the resolution to demonstrate the cytoplasmic boundaries between neighboring glial cells. However, the spacing of their nuclei-crowded in some places, but well spread out in others-suggests that the extent of their cytoplasm varies from one cell to the next. As a rough estimate, one can divide the total length of all the peripheral nerves sampled $(5,745 \mu \mathrm{m})$ by the 68 nuclei to calculate an average cell length to be about $70 \mu \mathrm{m}$. That calculation assumes no overlap between neighboring glial cells; actually, such overlapping can occur, as demonstrated by Peters (1963). 
Figure 5 shows the relation between glia and PNS neurites in SBSEM sections through the nuclear region of glial cells. Neurites (indicated by single arrows) are located in deep invaginations in the glial cytoplasm. The appearance of individual neurites varies from relatively lucent to very dense, and their diameters range mostly between 0.1 and $0.3 \mu \mathrm{m}$, although a few of the lucent variety can range up to about $1 \mu \mathrm{m}$. The number of neurites running in each invagination varies from one (Figure $5 \mathrm{a}$ ) to half a dozen or more (Figure $5 \mathrm{~b}$ ). The surface of the glia-neurite complex is surrounded by a thin external lamina. In sum, at the fine-structural level, the glia/neurite complexes in the PNS of the Asymmetron tail closely resemble the association of neurites with nonmyelinated Schwann cells (Remak cells) of vertebrates (Harty \& Monk, 2017), as was first demonstrated in cephalochordates for Branchiostoma by Peters (1963).
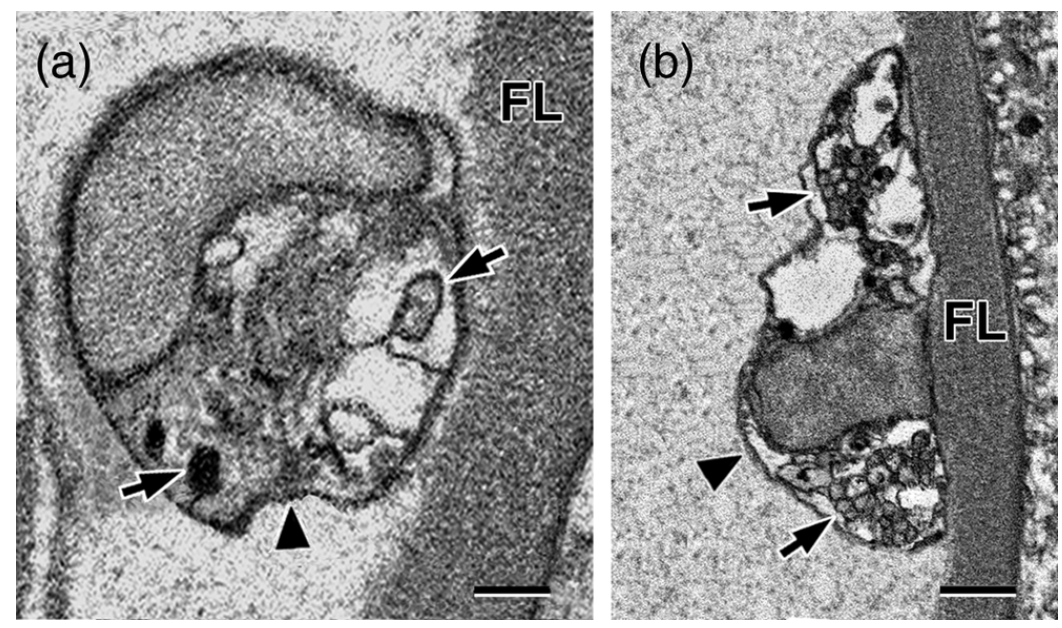

FIGURE 5 Cross-section of a peripheral nerve through the nuclear region of a glial cell adjacent to the collagen fibril layer (FL); the glial cell/neurite complex is surrounded by an external lamina (arrowhead). (a) Single neurites (single arrows) occupy invaginations in the relatively lucent cytoplasm of the glial cell. Scale line $=0.5 \mu \mathrm{m}$. (b) Small bundles of neurites (single arrows) occupy invaginations in the glial cell cytoplasm. Scale line $=1 \mu \mathrm{m}$

In Asymmetron, the peripheral nerves in the dermis ultimately connect with the epidermal component of the PNS (described in section 3.7). Our SBSEM lacks the resolution for determining whether extensions of glial cells accompany the neurites as they enter the epidermis. In vertebrates, glial extensions may accompany peripheral neurites into the epidermis, but only for a short distance (Whitear, 1983). In Asymmetron, the glial component evidently does not accompany PNS neurites very far after they enter the epidermis because TEM of Branchiostoma shows neurites without a glial sheath running between epidermal cells of embryos (Yasui, Tabata, Ueki, Uemura, \& Zhang, 1998) and adults (Bereiter-Hahn, 1984).

\subsection{Peripheral nerves reaching the epidermis via fenestrae in the collagen fibril layer}

The peripheral nerves exit from the dermis to the epidermis-either as en passant branches or at their posterior terminations (only a few end blindly within the dermis). The nerves traverse the collagen fibril layer at exit sites we will call fenestrae. In Figure 3a,b, the position of each fenestra is shown by an up- or downpointing white arrow (in actual fact, each of them exits directly toward the viewer). We measured the diameters of the nerves passing through the 117 fenestrae on both sides of the sampled tail region. The size distribution is shown graphically in Figure 6. The nerve diameters ranged from 0.05 to $0.60 \mu \mathrm{m}$ with a mean of $0.27 \mu \mathrm{m}$ $(S D=0.14)$. Previous information on nerves passing through fenestrae in adult cephalochordates is limited to a few fortuitously-cut TEM sections of Branchiostoma (Baatrup, 1981; Ruppert, 1997; Schulte \& Riehl, 1977); the exiting nerves were larger than in Asymmetron $(\sim 1 \mu \mathrm{m}$ in diameter), possibly due to species differences and/or to sampling different body regions. 


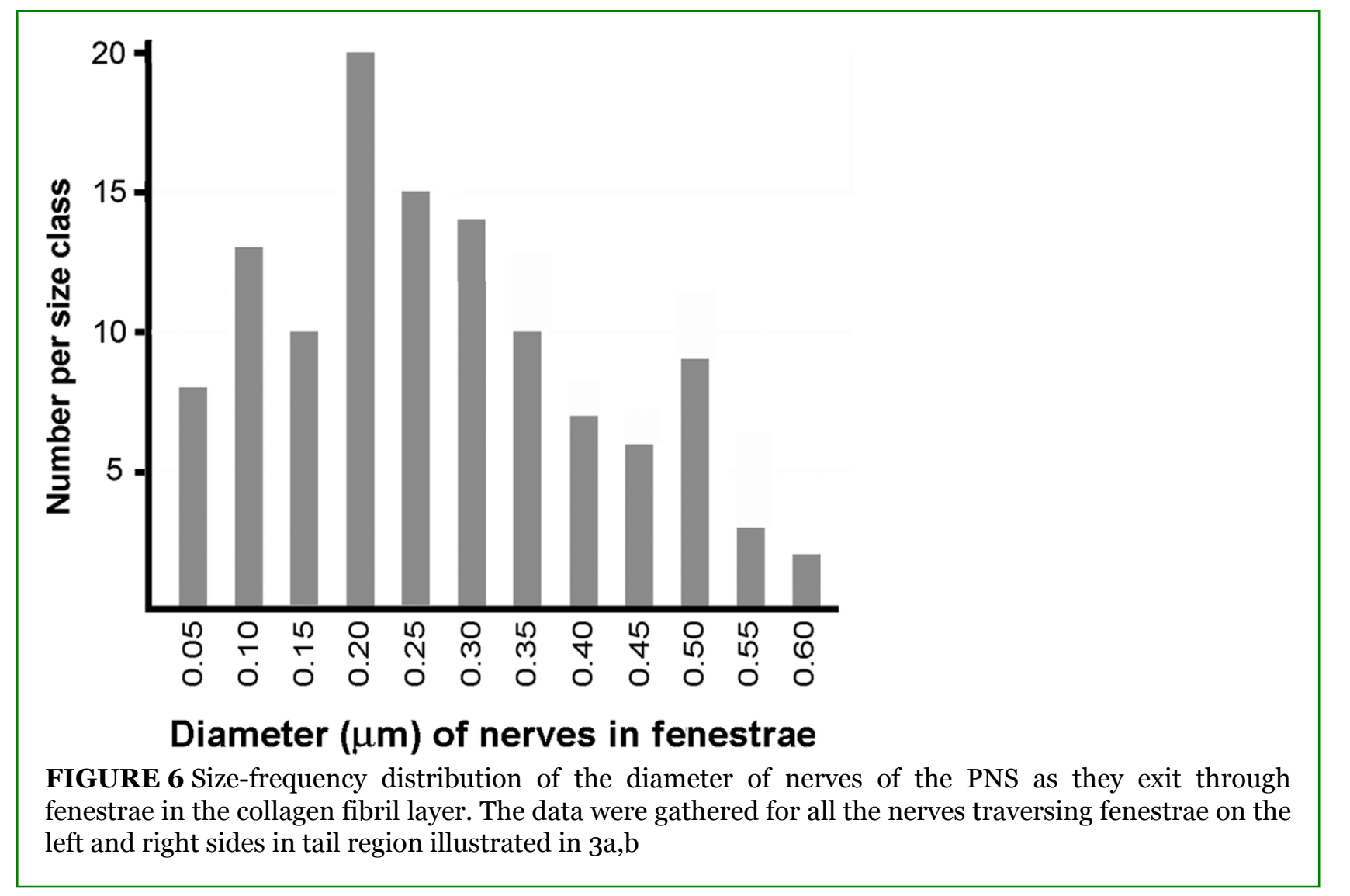

In Asymmetron, the individual nerve passing through a given fenestra probably consists of several neurites and perhaps an extension of glial cell cytoplasm. If one considers the left side of the sampled region, each of the 66 fenestrae accommodates an average of 4 or 5 neurites (calculated from epidermal sensory cell densities given in section 3.7 below). The nerves entering the fenestrae in the collagen fibril layer follow one of two different trajectories. About $10 \%$ of the nerves enter the layer and then run within it for about 5-20 $\mu \mathrm{m}$, gradually approaching its outer surface before exiting to the epidermis. Regions where nerves exit gradually through the fibril layer are indicated by red underlining in Figure 3a,b. A side view of such a nerve passing within the fibril layer is shown in $3 \mathrm{D}$ in Figure $7 \mathrm{a}$, and a sequence of individual SBSEM cross-sections showing the passage is illustrated in Figure $7 \mathrm{~b}-\mathrm{h}$. In contrast, most of the exiting nerves ( $90 \%)$, pass abruptly and almost perpendicularly through the collagen fibril layer (Figure $8 \mathrm{a}-\mathrm{d}$ ). The data presented here are static, and only dynamic studies could determine whether the nerves in the fenestrae become passively immured thereby tissue growth and/or actively dissolve a channel through the extracellular material to reach the epidermis, as discussed for nerves in general by Seeds, Siconolfi, \& Haffke (1997). 


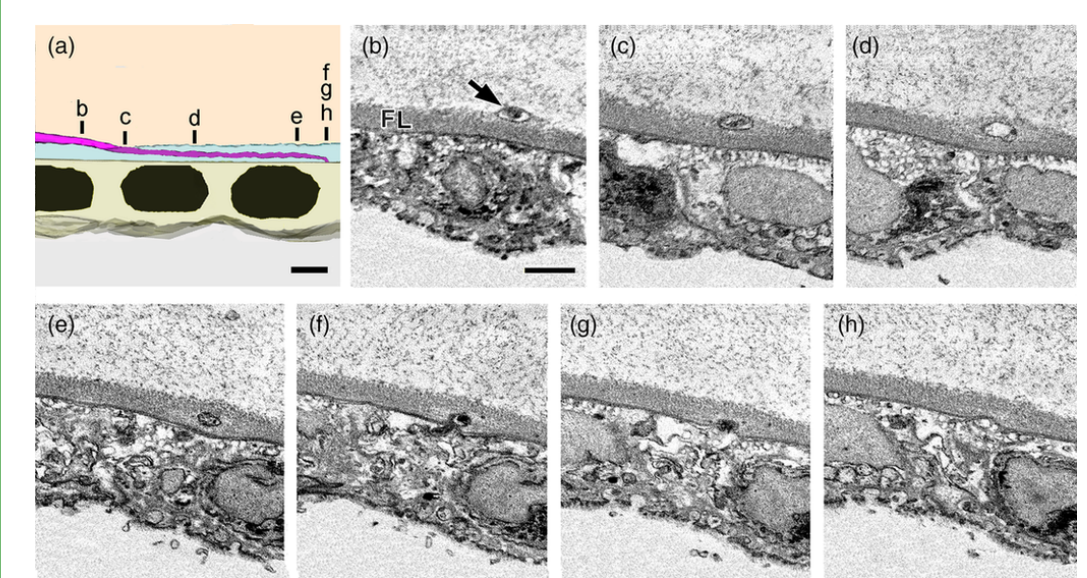

FIGURE 7 (a) SBSEM reconstruction of a region where a peripheral nerve (pink) angles slowly for about $10 \mu \mathrm{m}$ within the collagen layer (light blue) before entering the epidermis (light yellow). Lower case letters correspond to the cross-sections in $7 \mathrm{~b}-\mathrm{h}$; scale line $=2 \mu \mathrm{m}$. (b) Single SBSEM cross-section of a peripheral nerve (arrow) just before it enters the collagen fibril layer (FL); scale line (also applicable to $7 \mathrm{c}-\mathrm{h})=2 \mu \mathrm{m}$. $(\mathrm{c}-\mathrm{h})$ Series of SBSEM sections showing the foregoing nerve running within the collagen fibril layer at a shallow angle and then exiting to the epidermis

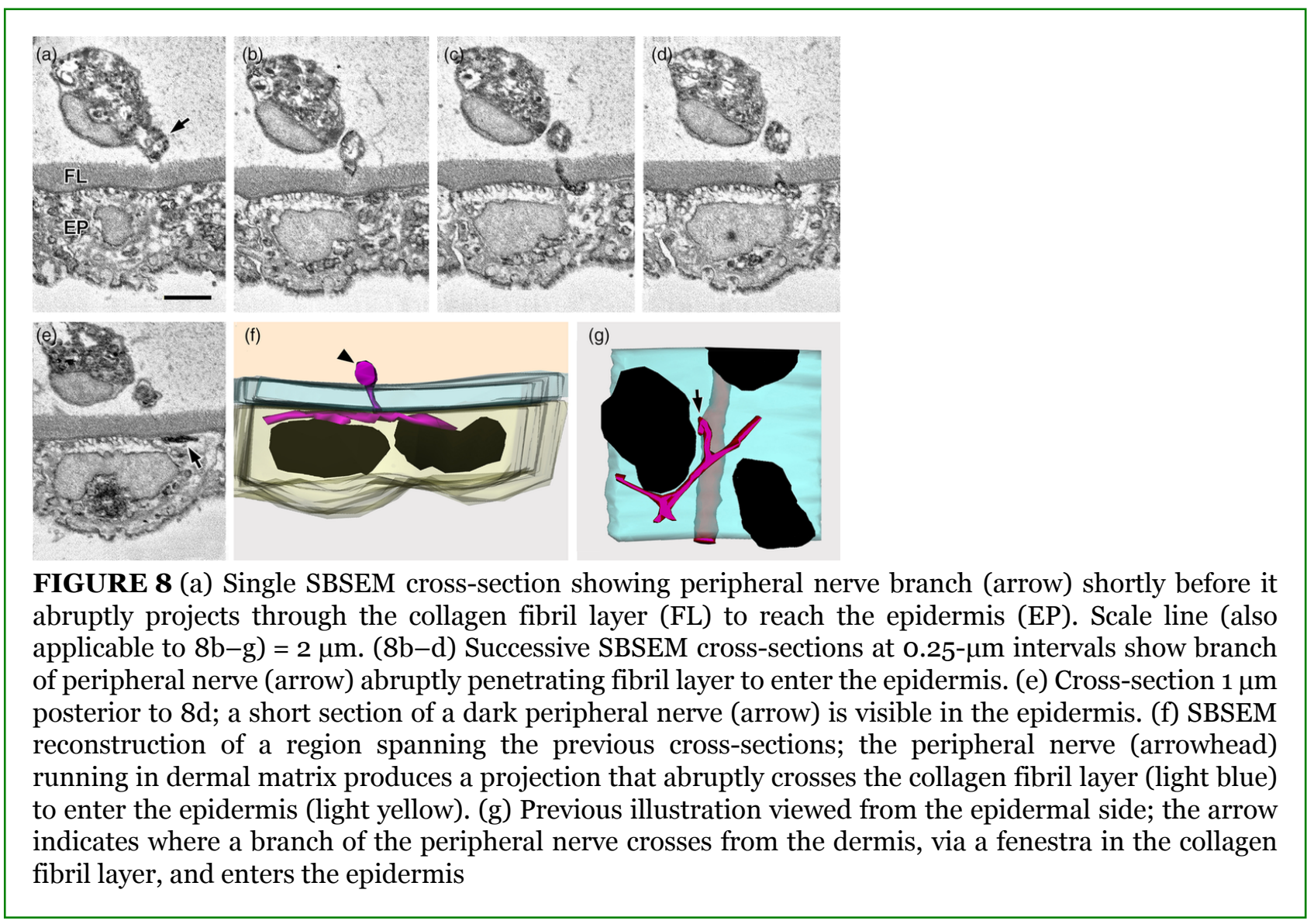

\subsection{Epidermal components of the PNS}


Neurites with denser cytoplasm can be detected after entering the epidermis (Figure 8e, arrow). Figure 8f,g shows SBSEM-based 3D models of an exited peripheral nerve as it begins branching among adjacent epidermal cells. Because of the low resolution of our SBSEM, we could not follow the branches very far. These branches are presumably the neurites of the Retzius bipolar cells that arborize among the epidermal cells (Demski, Beaver, \& Morrill, 1996; Kutchin, 1913). It has been suggested by Bone (1959) and by Demski, Beaver, \& Morrill (1996) that the Retzius bipolar cells could be homologous to the Rohon-Beard cells of vertebrates (Reyes, Haendel, Grant, Malancon, \& Eisen, 2003; Rovainen, 1982).

The epidermal part of the cephalochordate PNS also includes the perikarya of sensory cells. The two chief kinds of sensory cells were designated Type I and Type II in Branchiostoma by Schulte \& Riehl (1977). The apices of both are narrow and give rise to a single cilium, thus contrasting with the broad, nonciliated, polygonal surfaces of the general epidermal cells. We found the same two cell types in Asymmetron (Figure 9a-i).

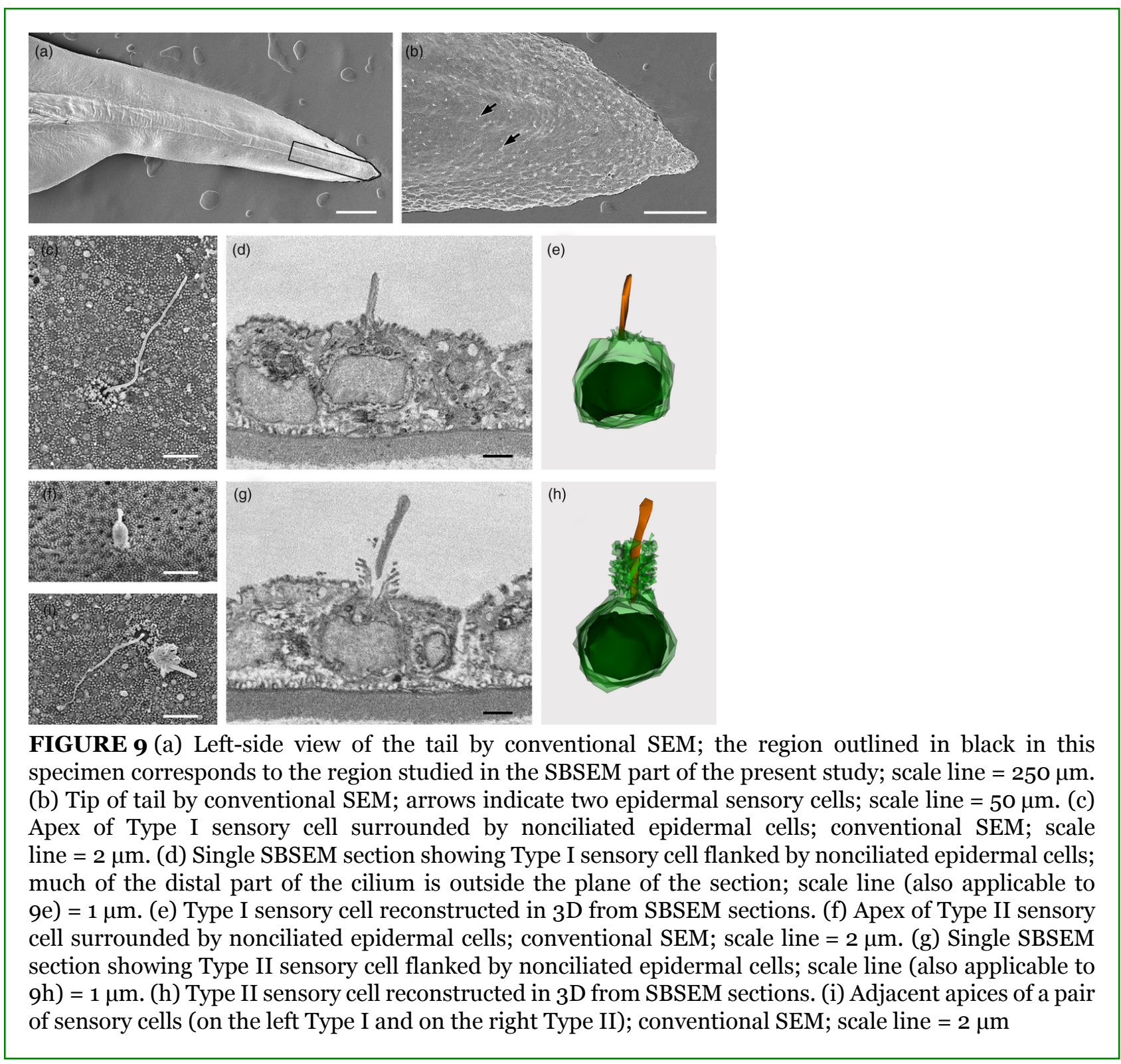

In Type I sensory cells, the apical cilium is roughly $10 \mu \mathrm{m}$ long and arises within a ring of microvilli that extend only slightly above the general surface of the epidermis (Figure 9c-e). Previous work on 
Branchiostoma has demonstrates that the perikaryon of each Type I cell belongs to a primary sensory neuron in that its basal axon passes through a fenestra in the collagen fibril layer (Baatrup, 1981; Lacalli \& Hou, 1999), traverses the dermis, and enters the dorsal nerve cord (Holland \& Yu, 2002). Presumably the Type I cells of Asymmetron are similar, but SBSEM at low magnification cannot trace their single, fine neurite.

In Type II sensory cells, the apical cilium is about $4 \mu \mathrm{m}$ long and has a slightly swollen tip. The basal half of the cilium is surrounded by long, crowded microvilli in a conspicuous cluster (Figure $\mathrm{gf}-\mathrm{h}$ ). In Branchiostoma, Type II cells produce short axons that synapse with neurites-presumably of Retzius bipolar cells, although this important point still needs to be convincingly demonstrated. At least some Type II cells send their axon through a fenestra to synapse in the dermis just beneath (Lacalli \& Hou, 1999), although other Type II cells probably form a synapse within the epidermis itself (as considered in section 3.8).

\subsection{Spatial relations of sensory cells and fenestrae; birth of sensory cells in pairs}

The spatial patterns of epidermal sensory cells and fenestrae were evaluated by calculating indices of aggregation from nearest neighbor measurements. Indices of aggregation can range from zero (no spacing at all, meaning that all the objects are in a single stack), through unity (random spacing), to a value of 2.15, which describes maximum spacing (which would be a regular hexagonal array). The index of aggregation for the fenestrae was 1.03, which would be expected for a distribution that is neither markedly clumped nor markedly regular.

In contrast, the index of aggregation for the sensory cells was 1.27 , indicating a weak tendency toward regular spacing. At first glance, it is surprising that the index is not higher because conventional SEM (Figure $9 \mathrm{~b}$ ) gives one the impression that the epidermal sensory cells are quite regularly distributed. However, when we gathered nearest-neighbor data from high-magnification SEM, we discovered several instances where pairs of nascent sensory cells were arising immediately adjacent to one another (Figure 9i); these pairings resulted in a lowering of the overall index of aggregation. Interestingly, one member of each pair was a Type I cell (with its cilium still in the process of formation) and the other was a Type II cell. This finding in Asymmetron is not without precedent: Lacalli and Hou (1999), in their study of a late metamorphic specimen of Branchiostoma, previously found Type I + Type II cell pairs in the epidermis. Although some kinds of hair cells in vertebrates are well known to arise as mirror-image pairs (Ghysen \& Dambly-Chauère, 2007; Rouse \& Pickles, 1991), the apparent production of two quite strikingly distinctive cell types, presumably from a single precursor, is quite uncommon. Lacalli and Hou (1999) tentatively suggested that the cephalochordate epidermis might include a pool of dividing, neural precursor cells differentiating into definitive sensory cells that ultimately degenerate and require replacement. Certainly, much more needs to be learned about the epidermal sensory cells: their detailed cell kinetics, their possible degeneration/regeneration cycles, and their possible separation from one another by lateral migration in the plane of the epidermis.

When the SBSEM data for the distribution of Type I and Type II sensory cells were mapped onto the SBSEM data for the distribution of fenestrae, it was found that many of the Type I and Type II sensory cells were separated from the nearest fenestra by several to many epidermal cell diameters (Figure 10). Evidently, the axon arising from the base of a Type I sensory cell must often make a horizontal detour in the epidermis before reaching a fenestra, and the short axons of many Type II sensory cells must make synaptic contact with the ramifying nerves in the epidermis at considerable distances from the nearest fenestra. The notion that each epidermal sensory cell sends its axon directly into an underlying fenestra (Baatrup, 1981; Holland \& Yu, 2002; Lacalli \& Hou, 1999) was evidently an oversimplification. 


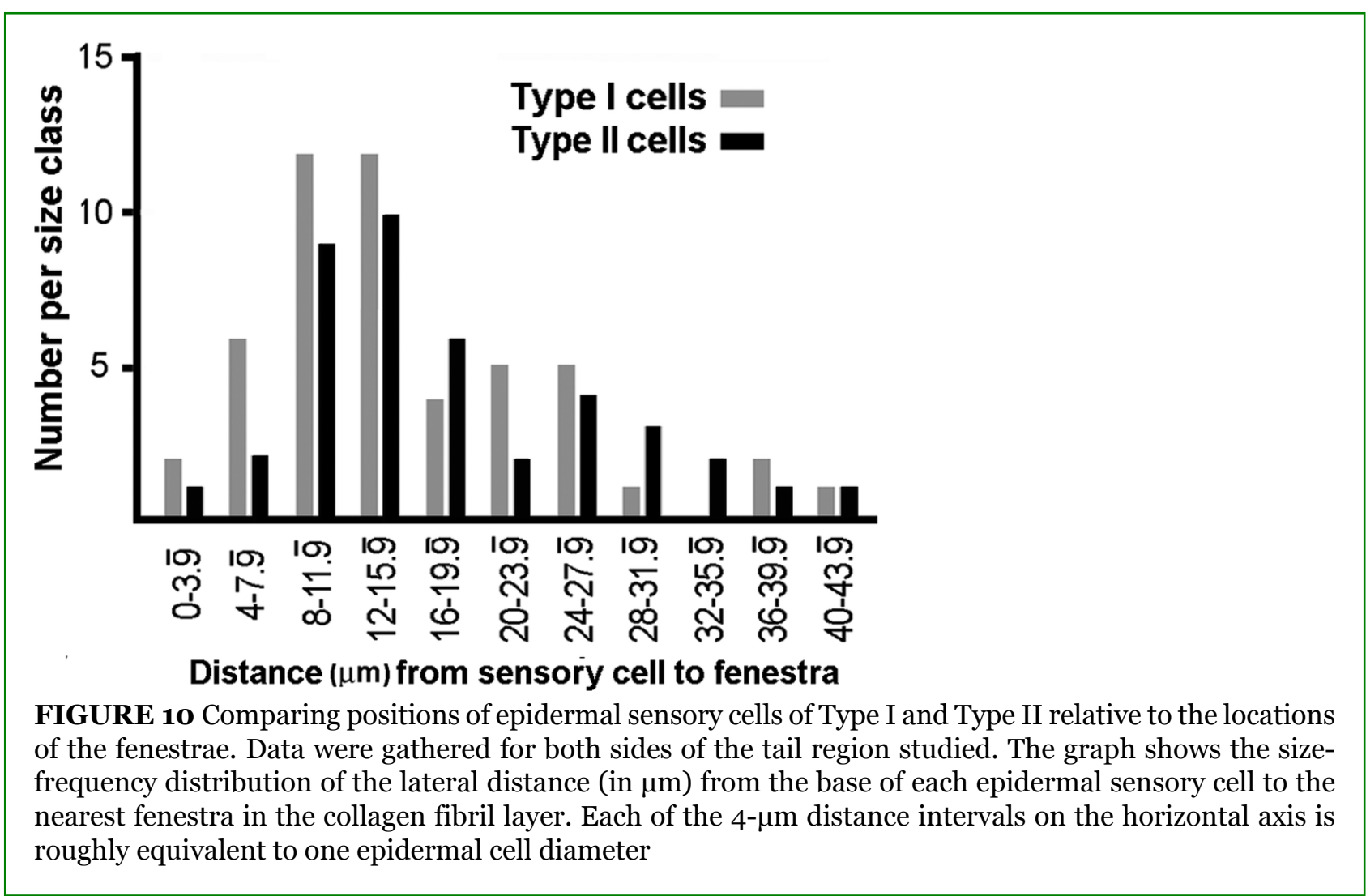

\section{DISCUSSION}

\subsection{A dense peripheral layer of dermis with fenestrae may be ancestral in chordates}

In adult cephalochordates, there is a continuous, dense layer of orthogonally arranged collagen fibrils at the periphery of the dermis. To reach the epidermis, nerves of the PNS pass through the dense collagen fibril layer in well-defined fenestrae. A similar collagen fibril layer is also the outermost component of the dermis in hagfishes (Clark, Crawford, King, Demas, \& Ueno, 2016) and lampreys (Krause, 1923a; Johnels, 1950; Razzauti, 1916). The foregoing references illustrate fine branches of the PNS crossing the fibril layer to the epidermis in fenestrae that are straight or sparingly branched, depending on the body region. The collagen fibril layer of agnathans is considerably thicker than that of cephalochordates, but this is due, at least in part, to the much larger adult body sizes of the former.

In teleosts, the dermis in scale-free regions is like that of hagfishes and lampreys in having a dense region of orthogonally arranged collagen fibrils as the most peripheral component of the dermis. In contrast, where scales are present, a loosely organized dermal region of scattered collagen fibrils and well-developed microvasculature overlies the dense collagen layer (Brown \& Wellings, 1970; Le Guellec, Morvan-Dubois, \& Sire, 2004; Nadol, Gibbins, \& Porter, 1969). The elasmobranch dermis resembles the scaled dermal regions of teleosts in having a deep layer of orthogonally arranged collagen fibrils beneath a well-vascularized region with scattered collagen fibrils (Krause, 1923a; Meyer \& Seegers, 2012; Motta, 1977). For elasmobranchs, Krause (1923a) illustrates a large nerve (about $25 \mu \mathrm{m}$ in diameter) crossing the dense collagen layer and then breaking up into a network of smaller nerves ramifying among the overlying loose weave of collagen fibrils to reach the epidermis. The elasmobranch pattern is also seen in the dermis of amphibians and birds in which the dermis consists of a loosely organized layer overlying a dense collagen fibril layer (Krause, 1922, 1923b). 
In reptiles (Rutland, Cigler, \& Kubale, 2019) and mammals (Kanitakis, 2001), the distinction between the superficial (papillary) dermis and the deeper (reticular) dermis is less conspicuous than in other vertebrates, and neither zone includes a dense orthogonally organized collagenous layer. In both the papillary and reticular dermis, the collagen fibrils tend to be bundled together into stouter fibers loosely organized into a mesh, and the peripheral nerves ramify through the rather spacious interstices in this mesh (Krause, 1921; Reinisch \& Tschachler, 2012).

The foregoing review suggests that a dense peripheral collagen layer penetrated by fenestrae for passage of the PNS, as seen in cephalochordates and lower vertebrates, is a basal chordate feature that has tended to be lost in more advanced vertebrates. Presumably, this ancestral chordate pattern was also present in the common ancestor of tunicates and vertebrates, but disappeared during tunicate evolution. Tunicates have lost all trace of a collagenous dermis, probably as a consequence of acquiring bacterial cellulose synthase through horizontal gene transfer (Sasakura, 2018) and evolving cellulose skeletons for body support-intraepidermally in appendicularians and supraepidermally in ascidians (Hirose et al., 2011).

\subsection{Comparing likely homologies for the sensory PNS among major chordate groups}

The present discussion will be limited to the sensory PNS because our work on Asymmetron did not include a motor component, which in cephalochordates is limited to more anterior regions-for example, the efferent innervation of the pterygial muscles (Bone 1961). Moreover, the sensory motor PNS is not prominent in cephalochordates because the trunk musculature synapses directly on the surface of the central nervous system (Ruppert, 1997). When one compares the sensory PNS of cephalochordates and vertebrates, the most likely homology is between neurons with intramedullary perikarya; namely, the Retzius bipolar cells of the former and the Rohon-Beard cells of the latter. On the other hand, a comparison of the extramedullary sensory neurons of cephalochordates and vertebrates reveals few similarities. The placode-derived sensory neurons of vertebrates (with the possible exception of the olfactory nerves) have little in common with the epidermal sensory neurons of cephalochordates (Schlosser, 2017). Moreover, the major contribution of neural crest to the vertebrate PNS (Pendergast \& Raible, 2014) has no counterpart in cephalochordates.

It is particularly interesting to relate the sensory PNS of tunicates to that of other chordates. The tunicate PNS appears unique in several respects. For example, tunicates, in contrast to other chordates, have no glial cell component in the PNS (Hartenstein \& Giangrande, 2018; Olsson, 1998). In addition, tunicates lack sensory neurons with intramedullary perikarya homologous to either the Retzius bipolar cells of cephalochordates or the Rohon-Beard cells of vertebrates (Glover \& Fritzsch, 2009). Consequently, the nerve endings that ramify among the epidermal cells of cephalochordates and vertebrates are lacking in tunicates.

In spite of the striking differences mentioned above, the extramedullary part of the sensory PNS of tunicates is comparable to that of vertebrates in some ways and to that of cephalochordates in other ways. This is due to what Hartenstein (2019) aptly refers to as the "chimeric" nature of the extramedullary PNS in larval tunicates. Many of the epidermal sensory neurons of larval ascidians derive from the neural plate boundary and have a molecular fingerprint resembling that of vertebrate neural crest and sensory placodes. In contrast, however, the epidermal sensory neurons along the ventral side of the tunicate tail develop under genetic controls broadly similar to those directing the differentiation of the epidermal sensory neurons of cephalochordates (Waki, Imai, \& Satou, 2015). Thus, the extramedullary sensory PNS of tunicates consists of a mixture of cephalochordate-like and vertebrate-like features.

In sum, during the evolution of the sensory PNS of chordates, it is likely that the component with intramedullary perikarya (Retzius bipolar cells) in cephalochordates carried forward into vertebrates as Rohon-Beard cells. In contrast, the extramedullary component originating from ventral eepidermis of cephalochordates was evidently replaced completely by sensory neurons derived from neural crest and placodes by time the earliest vertebrates appeared. 


\section{ACKNOWLEDGMENTS}

Personnel at the Bimini Biological Field Station (Sharklab) helped collect Asymmetron; Greg Rouse photographed the living lancelet; Kimberly Vanderpool (Scripps Research Institute, La Jolla) helped with conventional SEM; and Jennifer Santini and Marcella Erb of the UCSD School of Medicine Microscopy Core assisted with the SBSEM procedures. The SBSEM facility and staff support are funded by the UCSD School of Medicine Microscopy Core Grant P30 NSo47101. Cephalochordate research at SIO is supported by NSF Grant Number IOS 1353688. Our text was much improved by the critical comments of Linda Holland and Thurston Lacalli.

\section{CONFLICT OF INTEREST}

None declared.

\section{DATA AVAILABILITY STATEMENT}

Files supporting the findings of this study are available from the corresponding author upon reasonable request.

\section{REFERENCES}

Andrews, E. A. (1893). An undescribed acraniate: Asymmetron lucayanum. Studies from the Biological La boratory, Johns Hopkins University, 5, 213-247.

Baatrup, E. (1981). Primary sensory cells in the skin of amphioxus (Branchiostoma lanceolatum) (Cephaloc hordata). Acta Zoologica Stockholm, 62, 147-157.

Balfour, F. M. (1885). Comparative embryology (Vol. 2). London: MacMillan.

Bereiter-Hahn, J. (1984). Cephalochordata. In J. Bereiter-Hahn, A. G. Matoltsy, \& K. S. Richards (Eds.), Bio logy of the integument; volume I, invertebrates (pp. 817-825). Berlin: Springer.

Bone, Q. (1959). The central nervous system in larval acraniates. Quarterly Journal of Microscopical Scienc e, 100, 509-527.

Bone, Q. (1961). The organization of the atrial nervous system of amphioxus (Branchiostoma lanceolatum [Pallas]). Philosophical Transactions of the Royal Society B, 243, 241-269.

Borrett, S., \& Hughes, L. (2016). Reporting methods for processing and analysis of data from serial block fa ce scanning electron microscopy. Journal of Microscopy, 263, 3-9.

Braet, F., De Zanger, R., \& Wisse, E. (1997). Drying cells for SEM, AFM, and TEM by hexamethyldisilazane: A study on hepatic endothelial cells. Journal of Microscopy, 186, 84-87. 
Brown, G. A., \& Wellings, S. R. (1970). Electron microscopy of the skin of the teleost, Hippoglossoides elass odon. Zeitschrift für Zellforschung, 103, 149-169.

Butler, S. J., \& Bronner, M. E. (2015). From classical to current: Analyzing peripheral and spinal cord lineag e and fate. Developmental Biology, 398, 135-146.

Clark, A. J., Crawford, C. H., King, B. D., Demas, A. M., \& Uyeno, T. A. (2016). Material properties of hagfis h skin, with insights into knotting behaviors. Biological Bulletin, 230, 243-256.

Deerinck, T. J., Bushong, E. A., Lev-Ram, V., Tsien, R. Y., \& Ellisman, M. H. (2010). Enhancing serial blockface scanning electron microscopy to enable high resolution 3-D nanohistology of cells and tissues. Microsc opy and Microanalysis, 16(Suppl S2), 1138-1139.

Demski, L. S., Beaver, J. A., \& Morrill, J. B. (1996). The cutaneous innervation of amphioxus: A review incor porating new observations with DiI tracing and scanning electron microscopy. Israel Journal of Zoology, 4 2(Suppl), 117-129.

Denk, W., \& Horstmann, H. (2004). Serial block-face scanning electron microscopy to reconstruct three-di mensional tissue nanostructure. PLoS Biology, 2(11), e329.

Dogiel, A. S. (1903). Das periphere Nervensystem des Amphioxus (Branchiostoma lanceolaum). Anatomisc he Hefte (Erste Abteilung), 21, 145-213.

Donnelly, K. P. (1978). Simulations to determine the variance and edge effect of total nearest-neighbor dista nce. In L. Hodder (Ed.), Simulation studies in archaeology (pp. 91-95). Cambridge: Cambridge University Press.

Fiala, J. C. (2005). Reconstruct: A free editor for serial section microscopy. Journal of Microscopy, 218, 5 2-61.

Fritzsch, B., \& Northcutt, R. G. (1993). Cranial and spinal nerve organization in amphioxus and lampreys: E vidence for an ancestral craniate pattern. Acta Anatomica, 148, 96-109.

Fusari, R. (1889). Contribution à l'étude du système nerveux périphérique de l'Amphioxus lanceolatus. Arc hives Italiennes de Biologie, 11, 237-242.

Ghysen, A., \& Dambly-Chauère, C. (2007). The lateral line microcosmos. Genes \& Development, 21, 2118-2 130.

Glover, J. C., \& Fritzsch, B. (2009). Brains of primitive chordates. In L. R. Squire (Ed.), Encyclopedia of neu roscience (1st ed., pp. 439-448). Amsterdam: Elsevier. 
Hartenstein, V. (2019). Development of nervous systems of invertebrates. In J. H. Byrne (Ed.), The Oxford handbook of invertebrate neurobiology (pp. 1-88). Oxford: Oxford University Press.

Hartenstein, V., \& Giangrande, A. (2018). Connecting the nervous and immune systems in evolution. Comm unications Biology, 1(64), 64.

Harty, B. L., \& Monk, K. R. (2017). Unwrapping the unappreciated: Recent progress in Remak Schwann cell biology. Current Opinion in Neurobiology, 47, 131-137.

Heymans, J. F., \& van der Stricht, O. (1898). Sur le système nerveux de l'amphioxus et en particular sur la c onstitution et la genèse des racines sensibles. Mémoires Couronées et Mémoires Des Savants Étrangers Ac ademie Royale Des Sciences, Des Leteres et Des Beaux-Arts de Belgique, 56(3), 1-74.

Hirose, E., Nakashima, K., \& Nishino, A. (2011). Is there intracellular cellulose in the appendicularian tail e pidermis? A tale of the adult tail of an invertebrate chordate. Communicative \& Integrative Biology, 4, 76 8-771.

Holland, L. Z. (2009). Chordate roots of the vertebrate nervous system: Expanding the molecular toolkit. $N$ ature Reviews Neuroscience, 10, 736-746.

Holland, N. D. (2011). Spawning periodicity of the lancelet, Asymmetron lucayanum (Cephalochordata), in Bimini, Bahamas. The Italian Journal of Zoology, 78, 478-486.

Holland, N. D. (2018). Formation of the initial kidney and mouth opening in larval amphioxus studied with serial blockface scanning electron microscopy (SBSEM). EvoDevo, 9, 16.

Holland, N. D., Panganiban, G., Henyey, E. L., \& Holland, L. Z. (1996). Sequence and developmental expres sion of AmphiDll, an amphioxus Distal-less gene transcribed in the ectoderm, epidermis and nervous syste m: Insights into evolution of craniate forebrain and neural crest. Development, 122, 2911-2920.

Holland, N. D., \& Yu, J. K. (2002). Epidermal receptor development and sensory pathways in vitally stained amphioxus (Branchiostoma floridae). Acta Zoologica Stockholm, 83, 309-319.

Johnels, A. G. (1950). On the dermal connective tissue of the head of Petromyzon. Acta Zoologica Stockhol $m$, 31, 177-185.

Johnston, J. B. (1905). The cranial and spinal ganglia of the viscero-motor roots in amphioxus. Biological $B$ ulletin, 9, 112-127.

Kaltenbach, S. L., Yu, J. K., \& Holland, N. D. (2009). The origin and migration of the earliest-developing se nsory neurons in the peripheral nervous system of amphioxus. Evolution \& Development, 11, 142-151. 
Kanitakis, J. (2001). Anatomy, histology and immunochemistry of human skin. European Journal of Derm atology, 12, 390-399.

Krause, R. (1921). Säugetiere. In Mikroskopische Anatomie der Wirbeltiere in Einzeldarstellungen (Vol. I). Berlin: De Gruyter.

Krause, R. (1922). Vögel und Reptilien. In Mikroskopische Anatomie der Wirbeltiere in Einzeldarstellunge $n$ (Vol. II). Berlin: De Gruyter.

Krause, R. (1923a). Teleostier, Plagiostomen, Zyklostomen und Leptokardier. In Mikroskopische Anatomie der Wirbeltiere in Einzeldarstellungen (Vol. IV). Berlin: De Gruyter.

Krause, R. (1923b). Amphibien. In Mikroskopische Anatomie der Wirbeltiere in Einzeldarstellungen (Vol. I II). Berlin: De Gruyter.

Kutchin, H. L. (1913). Studies on the peripheral nervous system of amphioxus. Proceedings of the American Academy of Arts \& Sciences, 49, 571-624.

Lacalli, T. C., \& Hou, S. F. (1999). A reexamination of the epithelial sensory cells of amphioxus (Branchiosto ma). Acta Zoologica Stockholm, 8o, 125-134.

Langerhans, P. (1876). Zur Anatomie des Amphioxus lanceolatus. Archiv für Mikroskopische Anatomie, 1 2, 290-348.

Le Guellec, D., Morvan-Dubois, G., \& Sire, J. Y. (2004). Skin development in bony fish with particular emp hasis on collagen deposition in the dermis of the zebrafish (Danio rerio). International Journal of Develop mental Biology, 48, 217-231.

Lele, P. P., Palmer, E., \& Weddell, G. (1958). Observations on the integument of amphioxus, Branchiostom a lanceolatum. Quarterly Journal of Microscopical Science, 99, 421-440.

Lu, T. M., Luo, Y. J., \& Yu, J. K. (2012). BMP and Delta/notch signaling control the development of amphio xus epidermal sensory neurons: Insights into the evolution of the peripheral nervous system. Development, 139, 2020-2030.

Meyer, W., \& Seegers, U. (2012). Basics of skin structure and function in elasmobranchs: A review. Journal of Fish Biology, 8o, 1940-1967.

Motta, F. J. (1977). Anatomy and functional morphology of dermal collagen fibers in sharks. Copeia, 1977, 454-464. 
Nadol, J. B., Gibbins, J. R., \& Porter, K. R. (1969). A reinterpretation of the structure and development of th e basement lamella: An ordered array of collagen in fish skin. Developmental Biology, 20, 304-331.

Olsson, R. (1955). Structure and development of Reissner's fibre in the caudal end of amphioxus and some 1 ower vertebrates. Acta Zoologica Stockholm, 38, 167-198.

Olsson, R. (1998). Reissner's fiber mechanisms: Some common denominators. In A. Oksche, E. M. Rodrigu ez, \& P. Fernández-Llebrez (Eds.), The subcommissural organ: An ependymal brain gland (pp. 33-39). Be rlin: Springer.

Peddie, C. J., \& Collinson, L. M. (2014). Exploring the third dimension: Volume electron microscopy comes of age. Micron, 61, 9-19.

Pendergast, A., \& Raible, D. W. (2014). Neural crest cells and peripheral nervous system development. In P. A. Trainor (Ed.), Neural crest cells: Evolution, development, and disease (pp. 255-286). Amsterdam: Elsev ier.

Peters, A. (1963). The structure of the dorsal root nerves of amphioxus. An electron microscope study. Jour nal of Comparative Neurology, 121, 287-304.

Razzauti, A. (1916). Struttura del tegmento dei petromizonti: nervi ed organi cutanei del senso. Archivio Ita liano di Anatomia e di Embriologia, 15, 1-63.

Reichert, C. B. (1870). Zur Anatomie des Branchiostoma lubricum. Archiv für Anatomie, Physiologie Und Wissenschaftliche Medicin, 1870, 755-758.

Reinisch, C. M., \& Tschachler, E. (2012). The dimensions and characteristics of the subepidermal nerve plex us in human skin-Terminal Schwann cells constitute a substantial cell population within the superficial de rmis. Journal of Dermatological Science, 65, 162-169.

Retzius, G. (1898). Die Methyleneblaufärbung bei dem lebenden Amphioxus. Biologische Untersuchungen, Neue Folge, 8, 118-122.

Reyes, R., Haendel, M., Grant, D., Melancon, E., \& Eisen, J. S. (2003). Slow degeneration of zebrafish Roho n-beard neurons during programmed cell death. Developmental Dynamics, 229, 30-41.

Rohon, J. V. (1882). Untersuchungen über Amphioxus lanceolatus. Ein Beitrag zur vergleichenden Anatom ie der Wirbelthiere. Denkschriften der Kaiserlichen Akademie der Wissenschaften, Wien, Mathematisch- $N$ aturwissenschaftliche Classe, 42(2), 1-64. 
Rouse, G. W., \& Pickles, J. O. (1991). Paired development of hair cells in neuromasts of the teleost lateral lin e. Proceedings of the Royal Society B, 246, 123-128.

Rovainen, C. M. (1982). Neurophysiology. In M. W. Hardisty \& I. V. Potter (Eds.), The biology of lampreys (Vol. 4A, pp. 1-136). London: Academic Press.

Ruppert, E. E. (1997). Cephalochordata (Acrania). In F. W. Harrrison \& E. E. Ruppert (Eds.), Microscopic a natomy of invertebrates; volume 15, Hemichordata, Chaetognatha, and the invertebrate chordates (pp. 3 49-504). New York: Wiley-Liss.

Rutland, C. S., Cigler, P., \& Kubale, V. (2019). Reptilian skin and its special histological features. In C. Rutla nd \& V. Kubale (Eds.), Veterinary anatomy and physiology (no pagination). Vienna: IntechOpen.

Sasakura, Y. (2018). Cellulose production and the evolution of the sessile lifestyle in ascidians. Sessile Orga nisms, 35, 21-29.

Schlosser, G. (2017). From so simple a beginning-What amphioxus can teach us about placode evolution. $I$ nternational Journal of Developmental Biology, 61, 633-648.

Schulte, E., \& Riehl, R. (1977). Elektronmicroskopische Untersuchungen an den Oralcirren und der Haut vo n Branchiostoma lanceolatum. Helgoländer Wissenschaftliche Meeresuntersuchungen, 29, 337-357.

Seeds, N. W., Siconolfi, L. B., \& Haffke, S. P. (1997). Neuronal extracellular proteases facilitate cell migratio n, axonal growth, and pathfinding. Cell and Tissue Research, 290, 367-370.

Soledad-Ruiz, M., \& Anadon, R. (1991). Ultrastructural study of the filum terminale and caudal ampulla of $\mathrm{t}$ he spinal cord of amphioxus (Branchiostoma lanceolatum Pallas). Acta Zoologica Stockholm, 72, 63-71.

Studnicka, F. K. (1909). Vergleichende Untersuchungen über die Epidermis der Vertebraten. Anatomische Hefte, 39(issue 1), 1-267.

Suter, T. A. C. S., \& Jaworski, A. (2019). Cell migration and axon guidance at the border between central an d peripheral nervous system. Science, 365, eaaw8231.

Titze, B., \& Genoud, C. (2016). Volume scanning electron microscopy for imaging biological ultrastructure. Biology of the Cell, 108, 307-323.

Waki, K., Imai, K. S., \& Satou, Y. (2015). Genetic pathways for differentiation of the peripheral nervous syst em of ascidians. Nature Communications, 6, 8719. 
Wanner, A. A., Genoud, C., \& Friedrich, R. W. (2016). 3-dimensional electron microscopic imaging of the ze brafish olfactory bulb and dense reconstruction of neurons. Scientific Data, 3, 160100.

Welsch, U. (1968). Beobachtungen über die Feinstruktur der Haut und des äusseren Atrialepithels von Bra nchiostoma lanceolatum Pall. Zeitschrift für Zellforschung, 88, 565-575.

Whitear, M. (1983). The question of free nerve endings in the epidermis of lower vertebrates. Acta Biologic a Hungarica, 34, 303-319.

Yasui, K., Tabata, S., Ueki, T., Uemura, M., \& Zhang, S. C. (1998). Early development of the peripheral nerv ous system in a lancelet species. Journal of Comparative Neurology, 393, 414-425.

Zieger, E., Garbarino, G., Robert, N. S. M., Yu, J. K., Croce, J., Candiani, S., \& Schubert, M. (2018). Retinoic acid signaling and neurogenic niche regulation in the developing peripheral nervous system of the cephaloc hordate amphioxus. Cellular and Molecular Life Sciences, 75, 2407-2429. 